\title{
STUDY OF FUNCTIONAL OUTCOME OF DISTAL FEMUR FRACTURES TREATED BY OPEN REDUCTION AND INTERNAL FIXATION WITH LOCKING COMPRESSION PLATE
}

\author{
R. Sahaya Jose', N. Gopala Krishnan² \\ ${ }^{1}$ Assistant Professor, Department of Orthopaedics, Sree Mookambika Institute of Medical Sciences. \\ ${ }^{2}$ Assistant Professor, Department of Orthopaedics, Sree Mookambika Institute of Medical Sciences.
}

\section{ABSTRACT}

\section{BACKGROUND}

Distal femur fractures account for about $7 \%$ of all femur fractures. These fractures can lead to knee stiffness and have the tendency to collapse into varus. The management of distal femur fractures has seen a paradigm shift from nonoperative measures to biological fixation and evolution of modern implants like Locking Compression Plate has been used in current times. With the use of Locking Compression Plate double plating can be avoided. In our study, we have evaluated the short-term Functional Outcome of patients who underwent open reduction internal fixation with Locking Compression Plate using Sander's criteria. Ours is both prospective and retrospective study of 20 patients with distal femur fractures treated operatively from April 2013 to October 2015. Our surgical modality of treatment is open reduction and internal fixation with locking compression plate using standard lateral approach. We have used AO classification to classify the distal femur fractures. With the results of our study, we have come to a conclusion that locking compression plate is a best option for both intra-articular and extra-articular distal femur fractures. It avoids the use of dual plating of distal femur which requires extensive soft tissue stripping in both sides, resulting in reduced blood supply, potential non-union and implant failure. Locking Compression Plate also helps in anatomical reduction of comminuted intra-articular fractures and it could also be used effectively in osteoporotic bone.

\section{KEYWORDS}

Distal Femur Fractures, Locking Compression Plate (LCP), Sander's Criteria, AO Classification.

HOW TO CITE THIS ARTICLE: Jose RS, Krishnan NG. Study of functional outcome of distal femur fractures treated by open reduction and internal fixation with locking compression plate. J. Evolution Med. Dent. Sci. 2016;5(35):1984-1991,

DOI: $10.14260 /$ jemds/2016/469

\section{INTRODUCTION}

Distal femur fractures account for about $7 \%$ of all femur fractures and have bimodal age distribution. That is, they occur with high energy trauma in younger patients and with low energy trauma in elderly. These fractures can lead to knee stiffness and have the tendency to collapse into varus. Up to $50 \%$ are intra-articular and require anatomical reduction. Both high and low energy injuries can cause metaphyseal comminution depending on the bone quality. Previously, the trend in treatment of these fractures leaned towards closed conservative management with traction, casting or combination of both. The problems with conservative management are limitation of reduction and difficulty in maintaining reduction. Associated complications of prolonged immobilisation, economic consideration of increased hospital stay also limits their utility. The management of distal femur fractures has seen a paradigm shift from non-operative measures to biological fixation and evolution of modern implants as well as specific techniques in current times. Internal fixation devices that have been used to treat these fractures include 95 degree angled blade plate, dynamic condylar screw plate, condylar buttress plate and retrograde supracondylar nail.

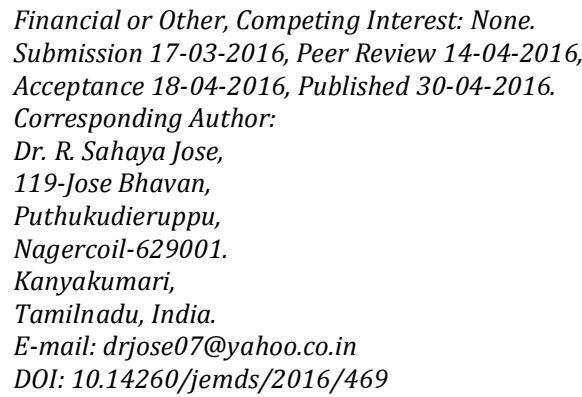

However, as the complexity of fractures needing treatment has changed from simple extra-articular supracondylar types to intercondylar and metaphyseal comminuted types, these implants may not be ideal.

Double plating and more recently locked plating has been advocated. However, with double plating there is extensive soft tissue stripping in both sides of femur, resulting in reduced blood supply and potential non-union and implant failure.

Distal femur locking compression plate has a smaller application device and allows both locking and compression screw fixation in the femur shaft. In our centre, we have decided to evaluate the short term functional outcome of operative treatment of distal femur fractures using Sander's et al criteria. We classified distal femur fractures using AO (Muller's) Classification. ${ }^{1}$

\section{AIMS AND OBJECTIVES}

To analyse the functional outcome of distal femur fractures treated with locking compression plate.

\section{MATERIALS AND METHODS}

The present study has totally 20 cases who took operative treatment for distal femur fractures from April 2013 to October 2015. It is a prospective and retrospective study. For all the cases, we used the Standard Lateral Approach. ${ }^{2}$ Out of 20 cases, 15 cases were closed fractures and 5 cases were grade-I compound fractures. Out of 20 cases, 13 were rightsided and 7 were left-sided distal femur fractures. The age group of patients ranges from 24 to 72 years.

\section{Follow-Up}

All patients were followed up regularly and they were assessed using Sander's et al scoring system. 
Patients were followed up at 6 weeks, 3 months, 6 months, 12 months and then yearly.

\section{Inclusion Criteria}

- Age 20 to 80 years.

- Closed or open (Gustillo Anderson ${ }^{3}$ grade I) fractures.

- AO type A, B and C fractures of distal femur.

\section{Exclusion Criteria}

- Patients with head injury and vascular injury.

- Age $<20$ years and $>80$ years.

- Patients not fit for surgical intervention.

\section{RESULTS}

In the period between April 2013 to October 2015, 20 patients with 20 fractures of the distal femur were taken up for this study. In our study, we did not have any bilateral distal femur fractures. All the patients were treated by distal femur Locking Compression Plate.

\section{Age Distribution}

In this study, age of the patients ranged from 24 to 72 years. The patients between the age group 31-40 years comprise the majority. The average age of the patients was 39.4 years.

\begin{tabular}{|c|c|}
\hline Age in Years & No. of Cases \\
\hline $20-30$ & 5 \\
\hline $31-40$ & 9 \\
\hline $41>50$ & 3 \\
\hline$>50$ & 3 \\
\hline
\end{tabular}

\section{Sex Distribution}

Out of 20 patients there were $12(60 \%)$ male and $8(40 \%)$ female in our study.

\begin{tabular}{|c|c|}
\hline Sex & No. of Cases \\
\hline Male & 12 \\
\hline Female & 8 \\
\hline
\end{tabular}

\section{Side Distribution}

Majority of the patients in this study 13 (65\%) sustained injury to the right side.

\begin{tabular}{|c|c|}
\hline Side & No. of Cases \\
\hline Right & 13 \\
\hline Left & 7 \\
\hline
\end{tabular}

\section{Mode of Injury}

In this study, 17 (85\%) patients sustained injury due to road traffic accident which comprises the majority.

\begin{tabular}{|c|c|}
\hline Mode of Injury & No. of Cases \\
\hline RTA & 17 \\
\hline Fall & 3 \\
\hline
\end{tabular}

\section{Type of Injury}

In our study, 15 patients had closed injury and 5 patients had compound fracture.

\begin{tabular}{|c|c|}
\hline Type of Injury & No. of Cases \\
\hline Closed & 15 \\
\hline Grade I compound & 5 \\
\hline
\end{tabular}

\section{Classification of Fractures}

The fractures were classified as per AO (Muller's) classification. Muller's type A1 comprises 7 (35\%) cases, with maximum incidence in this study.

\begin{tabular}{|c|c|}
\hline A0 Type & No. of Cases \\
\hline A1 & 7 \\
\hline A2 & 6 \\
\hline A3 & 3 \\
\hline B1 & - \\
\hline B2 & - \\
\hline B 1 & - \\
\hline C2 & 3 \\
\hline C3 & 1 \\
\hline
\end{tabular}

Time of Presentation After Injury

Out of 20 patients, 16 patients presented to the hospital within 24 hours, 4 cases presented between 2 to 7 days.

\begin{tabular}{|c|c|}
\hline Time of Presentation & No. of Cases \\
\hline $0-1$ day & 16 \\
\hline$<1$ week & 4 \\
\hline
\end{tabular}

\section{Associated Injuries}

\begin{tabular}{|c|c|}
\hline Type of Injury & No of Cases \\
\hline Tibial shaft \# ipsilateral & 2 \\
\hline Pelvic fractures & 1 \\
\hline Tibial condyle \# & 1 \\
\hline Clavicle \# & 1 \\
\hline Patella \# & 2 \\
\hline
\end{tabular}

\section{Time of Surgery After Admission}

In our study, 5 patients were operated within 2 days, 12 patients were operated between 3 to 5 days and 3 patients operated after 5 days.

\begin{tabular}{|c|c|}
\hline Duration in Days & No. of Cases \\
\hline$<2$ days & 5 \\
\hline $3-5$ days & 12 \\
\hline$>5$ days & 3 \\
\hline
\end{tabular}

\section{Mode of Anaesthesia}

In our study, majority of patients $11(55 \%)$ were operated under combined spinal and epidural anaesthesia.

\begin{tabular}{|c|c|}
\hline Type of Anaesthesia & No. of Cases \\
\hline GA & 1 \\
\hline Spinal & 3 \\
\hline Epidural & 5 \\
\hline Combined & 11 \\
\hline
\end{tabular}

\section{Rate of Radiological Union}

Out of 20 cases, 5 cases showed radiological union within 15 weeks and 14 cases between 16-30 weeks. Average rate of union is 20.5 weeks.

\begin{tabular}{|c|c|}
\hline Duration in Weeks & No. of Patients \\
\hline $0-15$ & 5 \\
\hline $16-30$ & 14 \\
\hline$>30$ & 1 \\
\hline
\end{tabular}

\section{Duration for Full Weight Bearing}

In our study, we started full weight bearing once there is evidence of radiological union. For majority of cases, we started full weight bearing at 16-20 weeks after surgery. 


\begin{tabular}{|c|c|}
\hline $\begin{array}{c}\text { Initiation of Full Weight } \\
\text { bearing in Weeks }\end{array}$ & No. of Cases \\
\hline $0-15$ & 1 \\
\hline $16-20$ & 11 \\
\hline $21-25$ & 4 \\
\hline$>26$ & 4 \\
\hline
\end{tabular}

\section{Range of Knee Flexion}

In our study, less than 70 degrees knee flexion was attained in $2(10 \%)$ cases, $71-100$ degrees knee flexion in $10(50 \%)$ cases and more than 100 degrees of knee flexion attained in $8(40 \%)$ cases.

\begin{tabular}{|c|c|}
\hline Knee Flexion in Degrees & No. of Cases \\
\hline$<70$ & 2 \\
\hline $71-100$ & 10 \\
\hline$>100$ & 8 \\
\hline
\end{tabular}

\section{COMPLICATIONS}

The complications observed in this study were 1 case with deep infection, 3 cases with superficial infection, 1 case with shortening, 1 case with implant breakage and 4 cases of knee stiffness.

\begin{tabular}{|c|c|}
\hline Complication & No. of Cases \\
\hline Superficial infection & 3 \\
\hline Deep infection & 1 \\
\hline Delayed union & Nil \\
\hline Non union & Nil \\
\hline Malunion & Nil \\
\hline Shortening & 1 \\
\hline Implant breakage & 1 \\
\hline Knee stiffness & 4 \\
\hline Neurovascular injury & Nil \\
\hline DVT & Nil \\
\hline
\end{tabular}

\section{Functional Results}

The function results of the study were assessed based on Sander's et al functional evaluation criteria. Out of 20 patients treated surgically, $1(5 \%)$ patient had excellent results, 13 $(65 \%)$ patients had good results, 5 (25\%) cases with fair result and $1(5 \%)$ patient had shown poor result. Hence, overall Locking Compression Plate has given reasonably a better functional outcome.

\begin{tabular}{|c|c|c|}
\hline Sander's et al Criteria & No. of Cases & Percentage \\
\hline Excellent & 1 & $5 \%$ \\
\hline Good & 13 & $65 \%$ \\
\hline Fair & 5 & $25 \%$ \\
\hline Poor & 1 & $5 \%$ \\
\hline
\end{tabular}

\section{DISCUSSION}

The treatment of complex distal femur fractures requires a thorough understanding of fracture biology. Treatment methods vary from conservative to internal fixation. Conservative treatment is associated with unsatisfactory outcomes. Conservative treatment using tibial traction for distal femoral fractures was reported by Mahorner and Bradburn [1933] $]^{4}$, with good final results in only few cases.

Operative treatment of distal femur fractures was revolutionised in the 1970s with the advent of AO implants, instruments and techniques. Dynamic condylar screws and blade plates require removal of large amount of bone for insertion, which limits their use in some fracture types.
Biomechanical studies revealed that gross loosening of the standard condylar buttress plate and DCS occurred because of toggle at the screw-plate interface. To address these issues, locking condylar plate was designed.

Locking compression plate decreases screw-plate toggle and motion at the bone-screw interface and provides more rigid fixation. Its unique biomechanical function is based on splinting rather than compression resulting in flexible stabilisation, avoidance of stress shielding and induction of callus formation.

In our study, 20 patients with distal femoral fractures were treated with distal femur locking compression plate and results were evaluated. Among 20 patients, 12 (60\%) patients were male and $8(40 \%)$ were female. The age of the patients in our study ranged from 24 to 72 with mean age of 39.4 years. Mode of injury was road traffic accident in 17 (85\%) patients and fall in $3(15 \%)$ patients. Right limb was commonly involved with $13(65 \%)$ fractures in right side and 7 (35\%) fractures involving left side. Average number of days from injury to surgery was 5 days with range from 1 day to 8 days. The operative time ranged from $60 \mathrm{~min}$. to $150 \mathrm{~min}$. with average of $102 \mathrm{~min}$. All fractures in our study were classified according to AO classification system. There were 7 (35\%) type A1, 6 (30\%) type A2, 3 (15\%) type A3, $3(15 \%)$ type C1 and $1(5 \%)$ type $\mathrm{C} 2$ fractures. Among these, $15(75 \%)$ patients had closed fracture and $5(25 \%)$ had grade I compound fracture.

Yeap EJ et al 5 in his study on 11 patients with distal femur fractures treated by locking compression plate, seven were male and four female patients. The patient's age ranged from 15 to 85 with mean age of 44 years. The causes of fractures were motor vehicle accident in 7 patients and fall in 4 patients. Seven fractures involved the right side and four involved the left. The average number of days from injury to surgery was 9.9 days with range of 4 to 18 days. The operative time ranged from $80 \mathrm{~min}$. to $180 \mathrm{~min}$. with an average of $119.2 \mathrm{~min}$. In his study, there were 4 type A1, 2 type A3, 1 type C1, 1 type $C 2$ and 3 type C3 fractures. Four (36.4\%) of the fractures were compound and seven (63.6\%) were closed fractures.

\begin{tabular}{|c|c|c|c|c|}
\hline Author & $\begin{array}{c}\text { No. of } \\
\text { Cases }\end{array}$ & $\begin{array}{c}\text { Open } \\
\#(\%)\end{array}$ & $\begin{array}{c}\text { Average } \\
\text { Age } \\
\text { (Years) }\end{array}$ & $\begin{array}{c}\text { Average } \\
\text { Follow-Up } \\
\text { (Months) }\end{array}$ \\
\hline $\begin{array}{c}\text { Yeap } \\
\text { et al }\end{array}$ & 11 & 36 & 44 & 9.7 \\
\hline $\begin{array}{c}\text { Hosam } \\
\text { et al }\end{array}$ & 23 & 8.7 & 48 & 32 \\
\hline $\begin{array}{c}\text { Kanabar } \\
\text { et al }\end{array}$ & 17 & 17.6 & 12 & 12 \\
\hline $\begin{array}{c}\text { Our } \\
\text { study }\end{array}$ & 20 & 25 & 39.4 & 14.2 \\
\hline
\end{tabular}

Hosam $\mathrm{M}$ et $\mathrm{al}^{6}$ in his study on 23 patients treated for distal femur fractures were in the age group ranging from 28 to 76 years, with an average of 48.25 years.

Fourteen cases $(60.7 \%)$ were right-sided and nine cases (39.13\%) were left-sided fractures. 15 (65.22\%) cases suffered from road traffic accident while $8(34.78 \%)$ patients suffered injury due to fall. 2 cases $(8.70 \%)$ were open fractures and 21 cases $(91.3 \%)$ were closed fractures. Nine cases $(39.13 \%)$ were operated upon within the week after injury, eight cases $(34.78 \%)$ in the second week and six cases (26.09\%) two weeks after injury. 
In our study, the range of knee flexion is 50 degrees to 120 degrees and average knee flexion is 98 degrees. Average time of union was 20.5 weeks with a range from 10 weeks to 34 weeks. All the patients were evaluated using Sander's et al scoring system and we had $70 \%$ excellent to good result. Various complications encountered in our study are $3(15 \%)$ patients with superficial infection which subsided with oral antibiotics, 1 (5\%) had deep infection which subsided with wound exploration and suction-irrigation, $1(5 \%)$ patient with limb shortening, 4 (20\%) patients had knee stiffness which needed physiotherapy treatment. Out of this, 1 patient came back with broken implant and re-fracture following native treatment for the knee stiffness and lost follow-up.
Kanabar et al, ${ }^{7}$ in his study noted bone union in a mean period of 17(Range, 10-36) weeks and mean range of knee flexion was 93 degrees (80-130 degrees). Complications encountered in his series included 1 patient with deep infection, 2 patients with superficial infection and 1 patient with implant breakage.

Hosam $\mathrm{M}$ et al, in his study had excellent and good results in 18 patients (78.26\%), with fair and poor results in 5 patients (21.74\%). In his study, various complications encountered were deep infection in one case $(4.35 \%)$, delayed union in three cases $(13.04 \%)$, knee joint stiffness in three cases $(13.04 \%)$ and shortening in two cases (8.70\%).

\begin{tabular}{|c|c|c|}
\hline Author & $\begin{array}{c}\text { Average } \\
\text { Knee Flexion } \\
\text { in Degrees }\end{array}$ & $\begin{array}{c}\text { Time for } \\
\text { Union } \\
\text { (Weeks) }\end{array}$ \\
\hline Yeap et al & 107 & 18 \\
\hline Hosam et al & 98 & - \\
\hline Kanabar et al & 93 & 17 \\
\hline Our study & 98 & 20.5 \\
\hline
\end{tabular}

\begin{tabular}{|c|c|c|c|c|c|}
\hline Author & $\begin{array}{c}\text { Deep Inf. } \\
(\%)\end{array}$ & $\begin{array}{c}\text { Sup. Inf } \\
\mathbf{( \% )}\end{array}$ & $\begin{array}{c}\text { Revision/Failure } \\
(\mathbf{\%})\end{array}$ & Mal-alignment/Shortening (\%) & $\begin{array}{c}\text { Knee Stiffness } \\
\text { (\%) }\end{array}$ \\
\hline Yeap et al & 3 & - & 1.5 & 4.5 & - \\
\hline Hosam et al & 4.3 & - & - & 8.7 & 13.4 \\
\hline Kanabar et al & 11.7 & - & 17.6 & - & 11.7 \\
\hline Our Study & 5 & 15 & 5 & 5 & 20 \\
\hline
\end{tabular}

Yeap et al, in his study reported average range of knee flexion 107 degrees and average time to union was 18 (Range, 6-36) weeks. In his study, there were $4(36.4 \%)$ excellent results, $4(36.4 \%)$ good results, $2(18.2 \%)$ fair results and $1(9 \%)$ poor result. Complications are one implant failure and one mal-alignment of lower limb.

\begin{tabular}{|c|c|c|}
\hline Author & $\begin{array}{c}\text { Scoring } \\
\text { System }\end{array}$ & $\begin{array}{c}\text { Excellent and } \\
\text { Good Results (\%) }\end{array}$ \\
\hline Yeap et al & Schatzker & 72.7 \\
\hline Hosam et al & Neer & 78.26 \\
\hline Kanabar et al & Neer & 88.23 \\
\hline Our study & Sanders & 70 \\
\hline
\end{tabular}

\section{Case 1: Excellent Result}

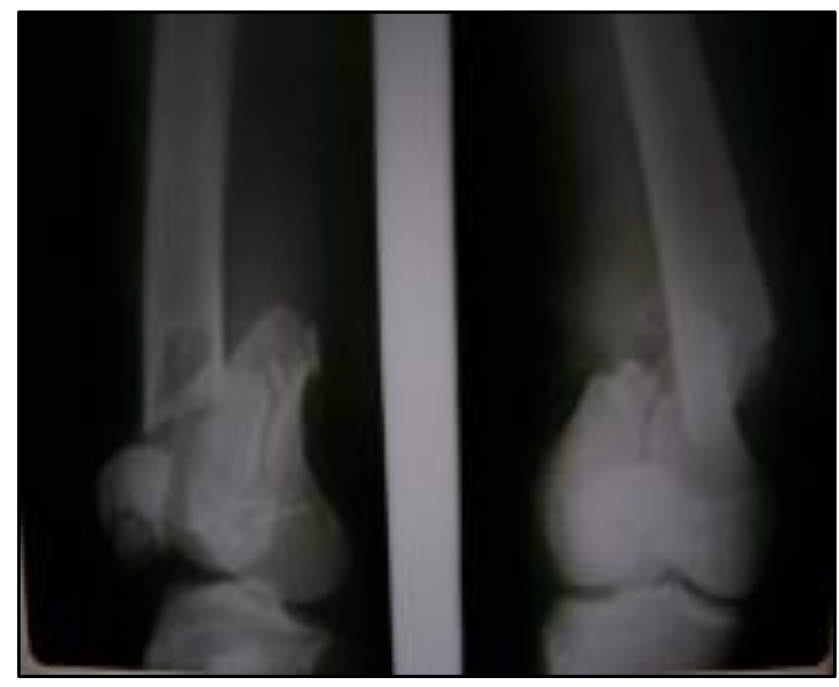

Pre-op

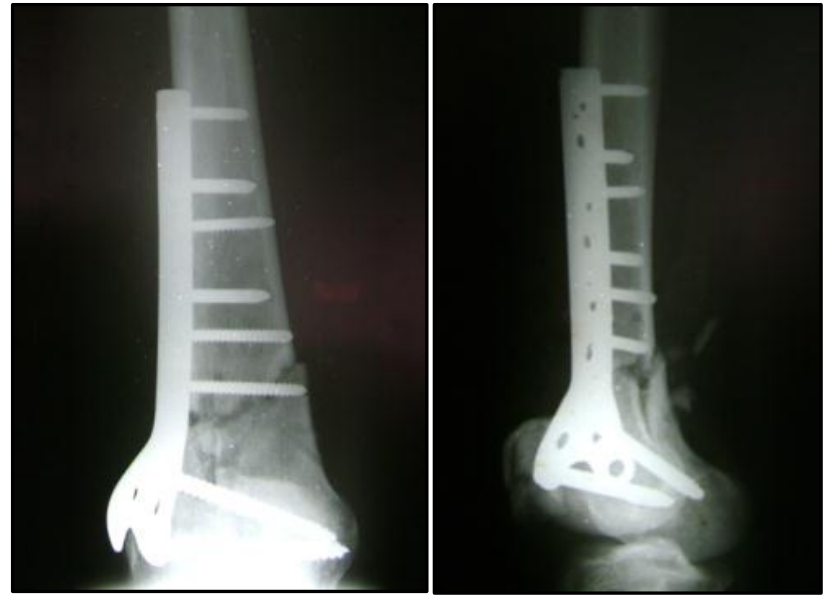

Post-op

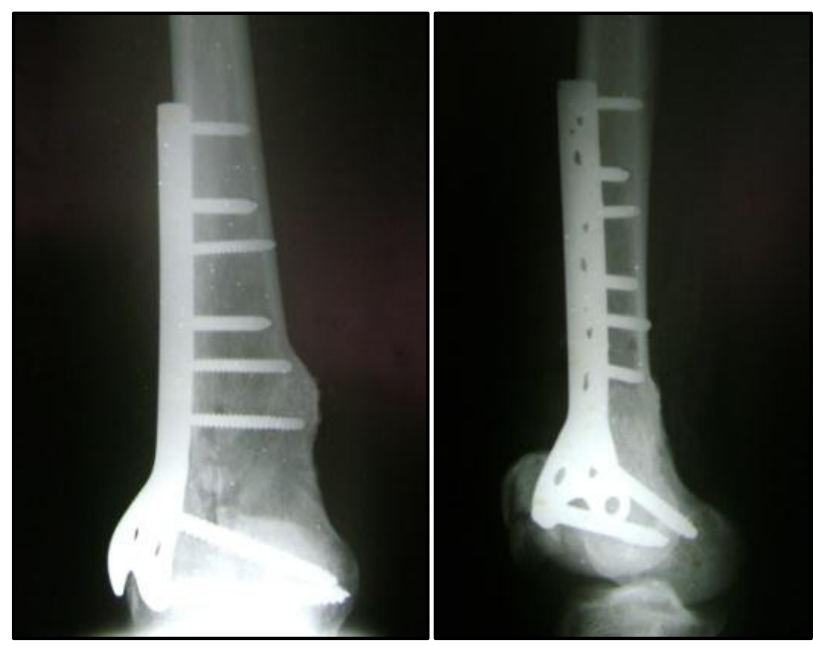

6 Months 


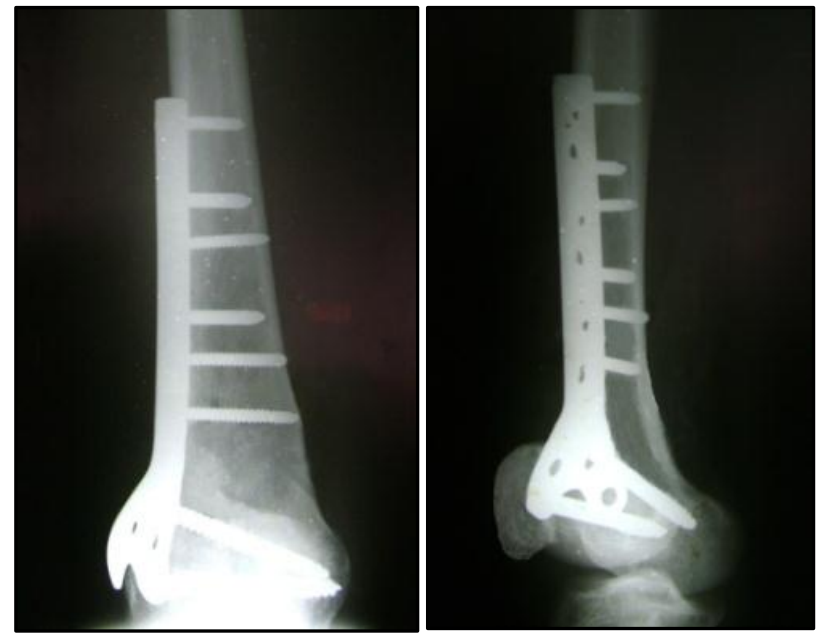

1 Year

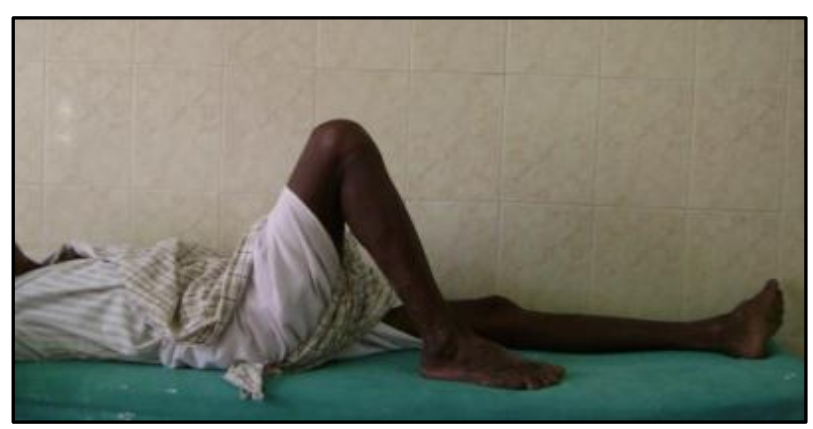

Knee Flexion

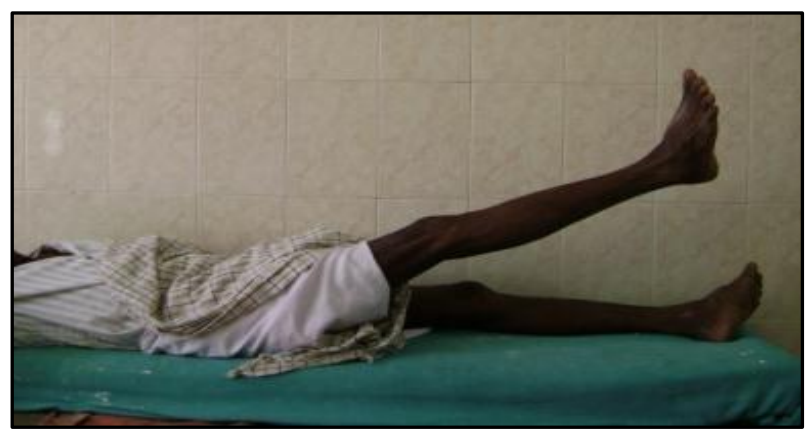

Knee Extension

CASE 2- Good Result

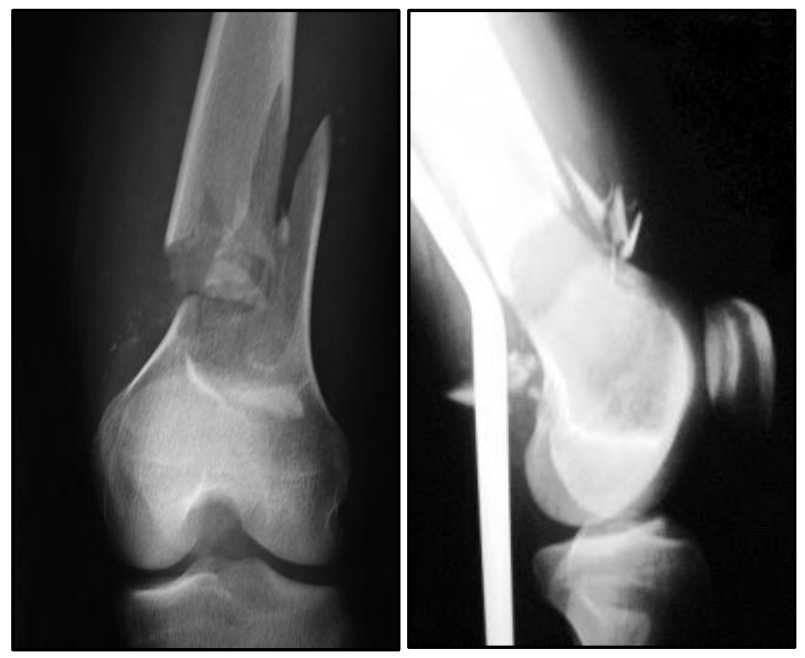

Pre-op

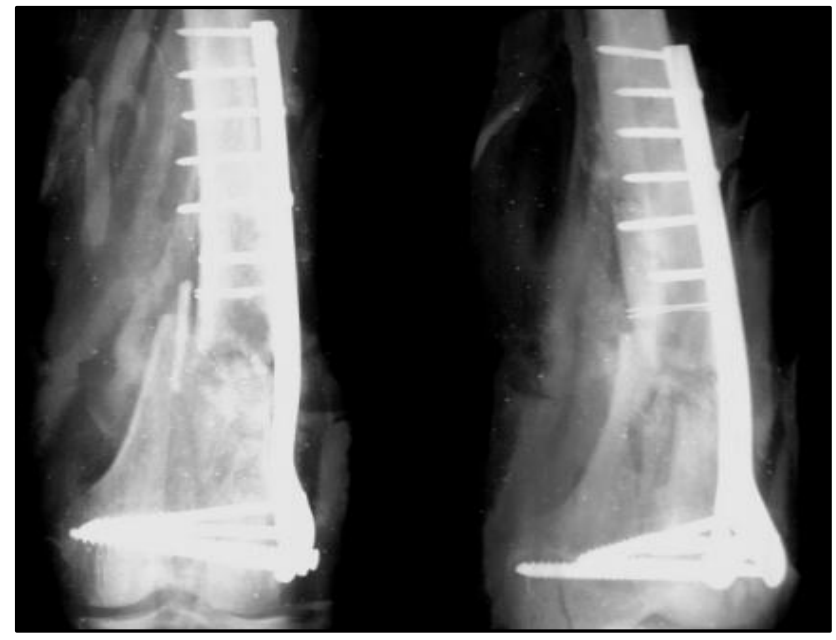

Post-op

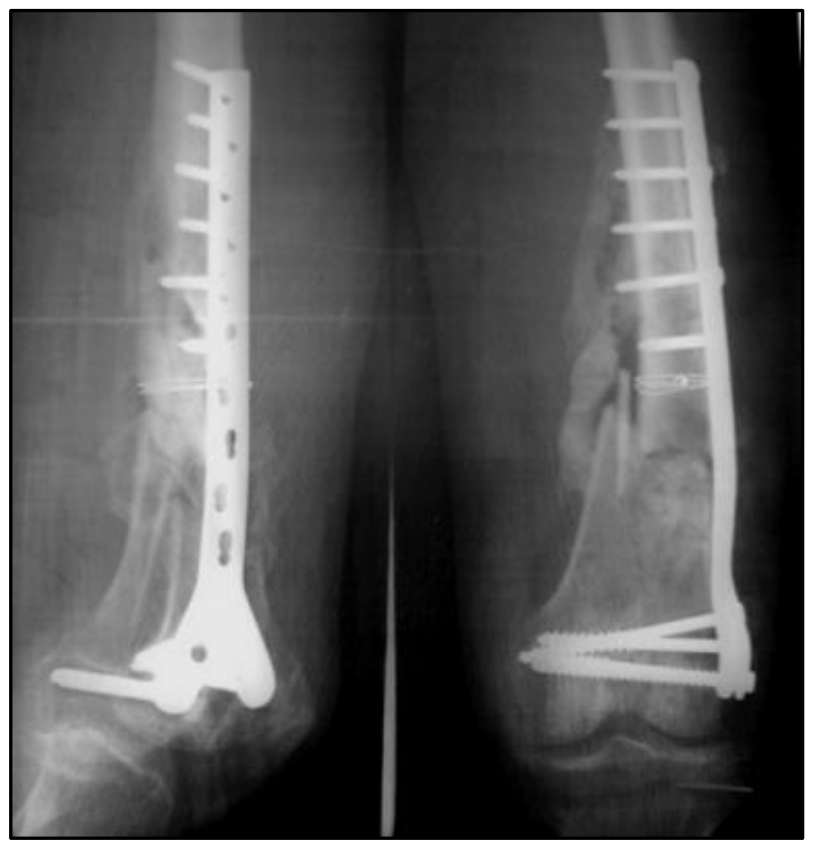

6 Months

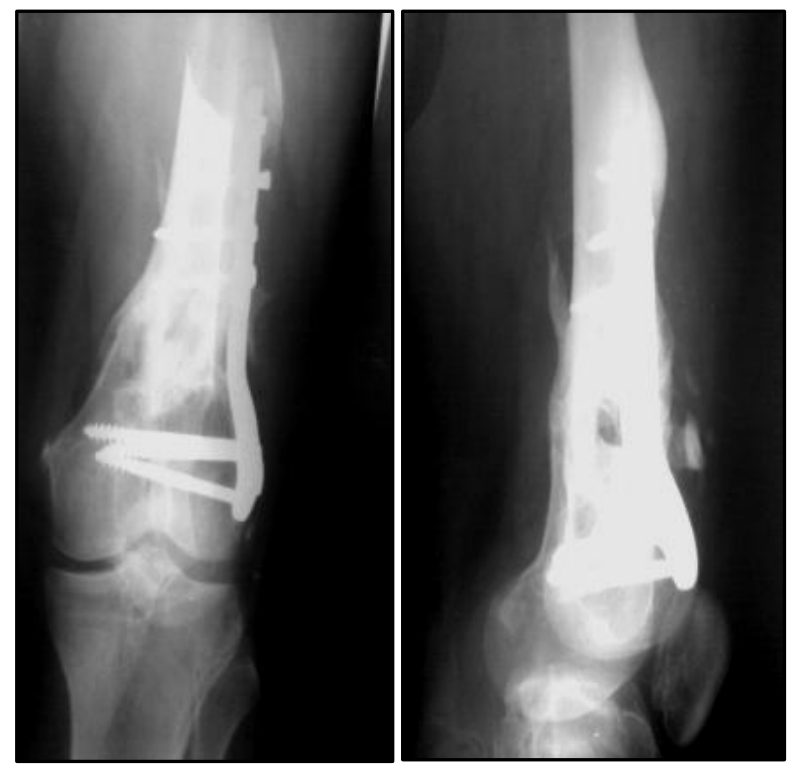

1 Year 


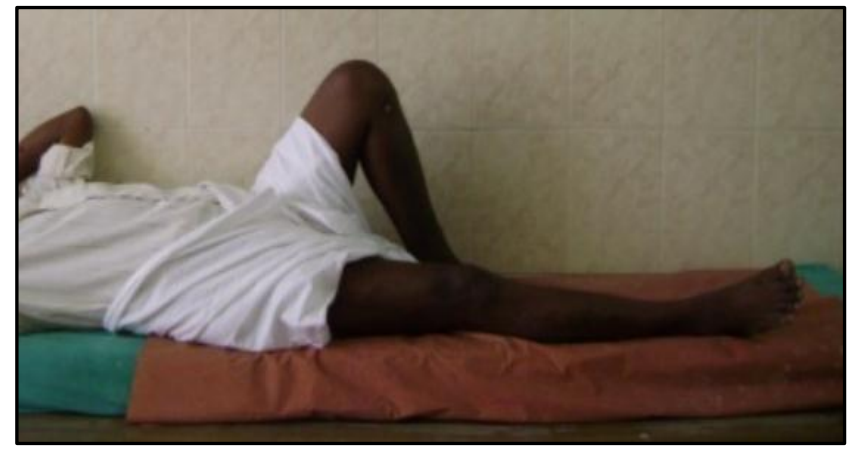

Knee Flexion

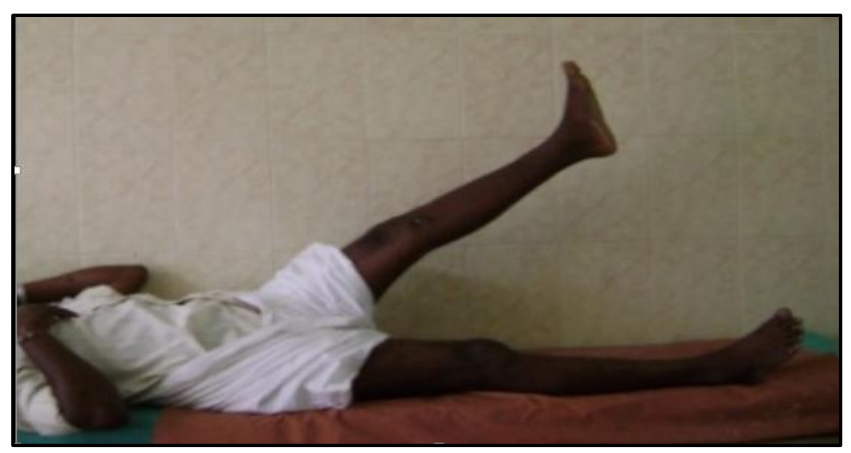

Knee Extension

\section{Case 3- Good Result}

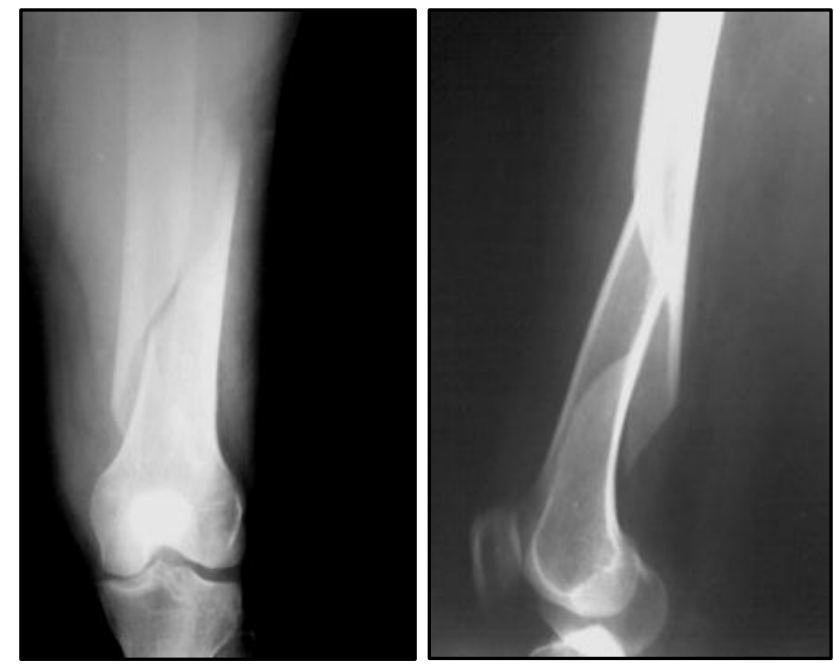

Pre-op

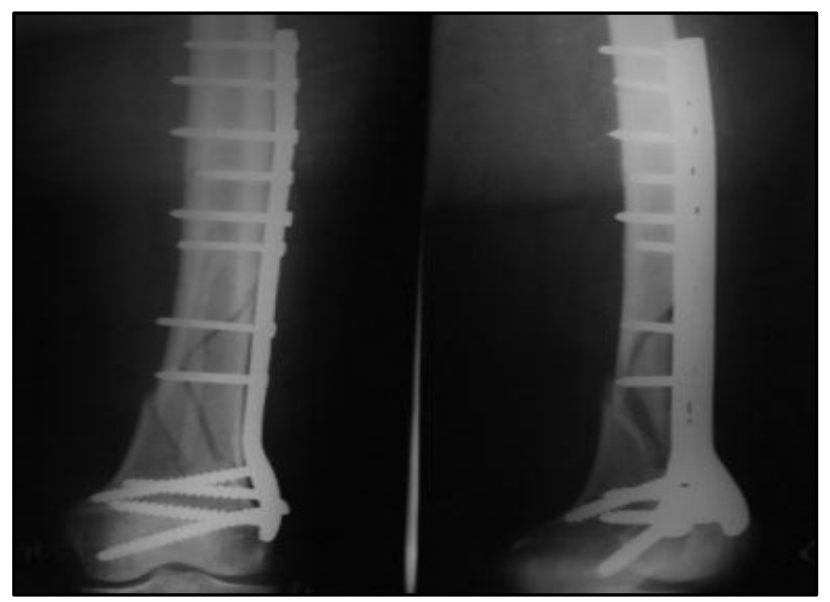

Post-op

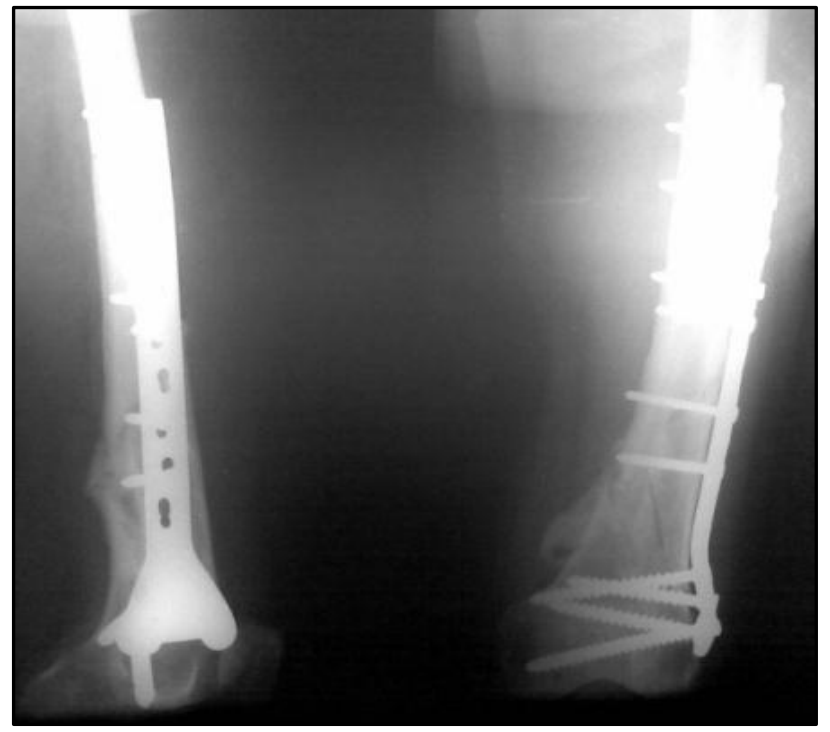

6 Months

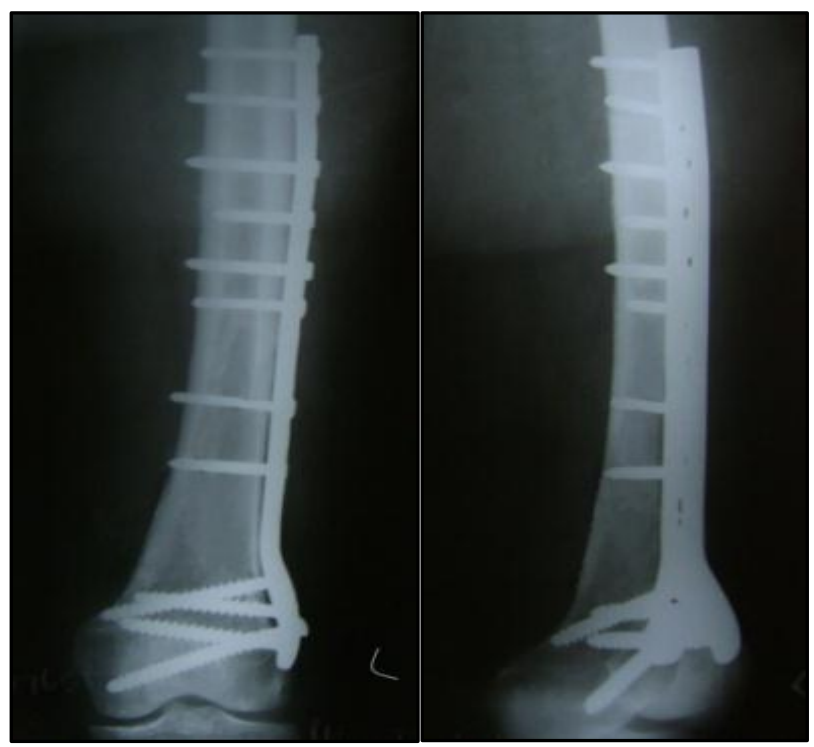

1 Year

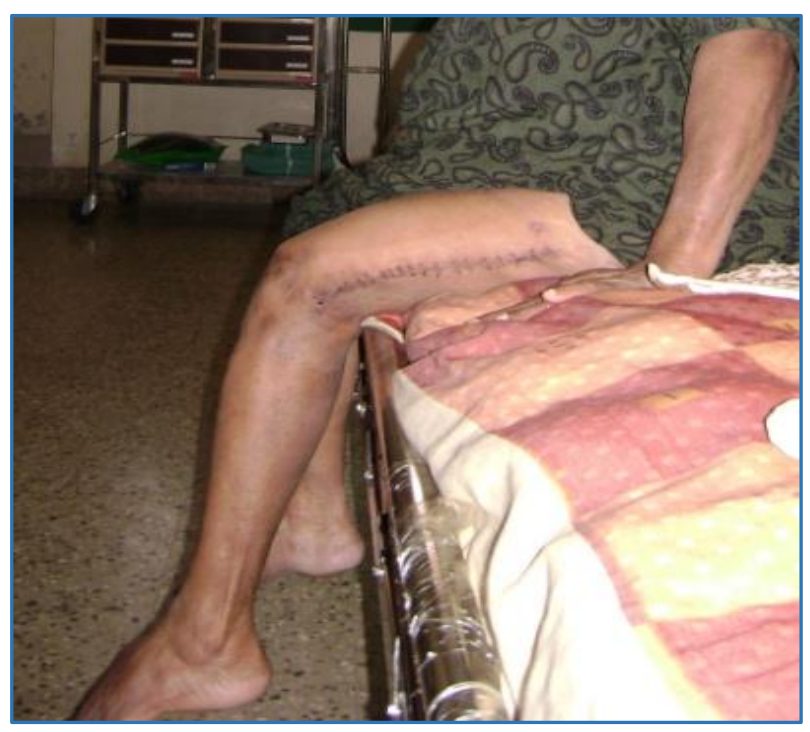

Knee Flexion 


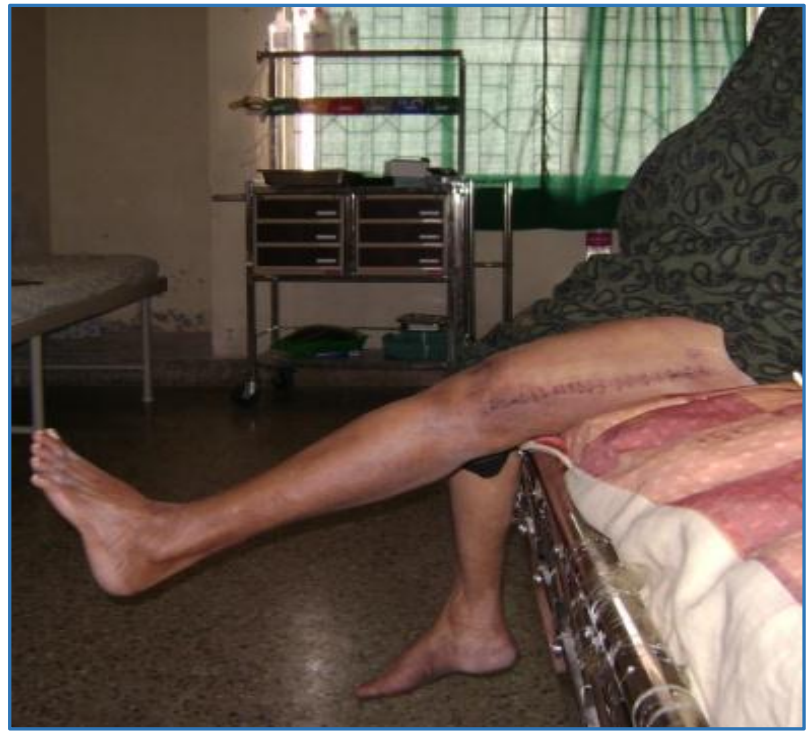

Knee Extension

\section{Case 4: Fair Result}

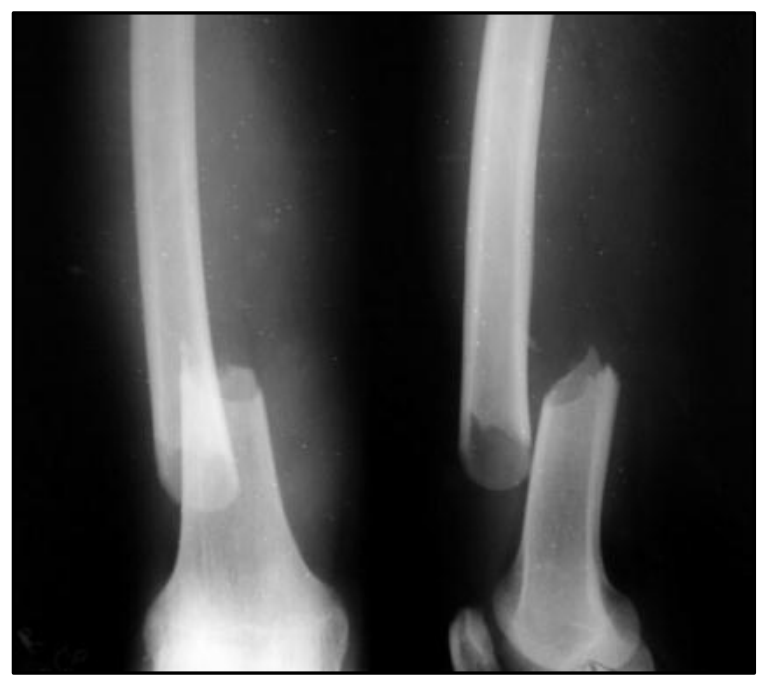

Pre-op

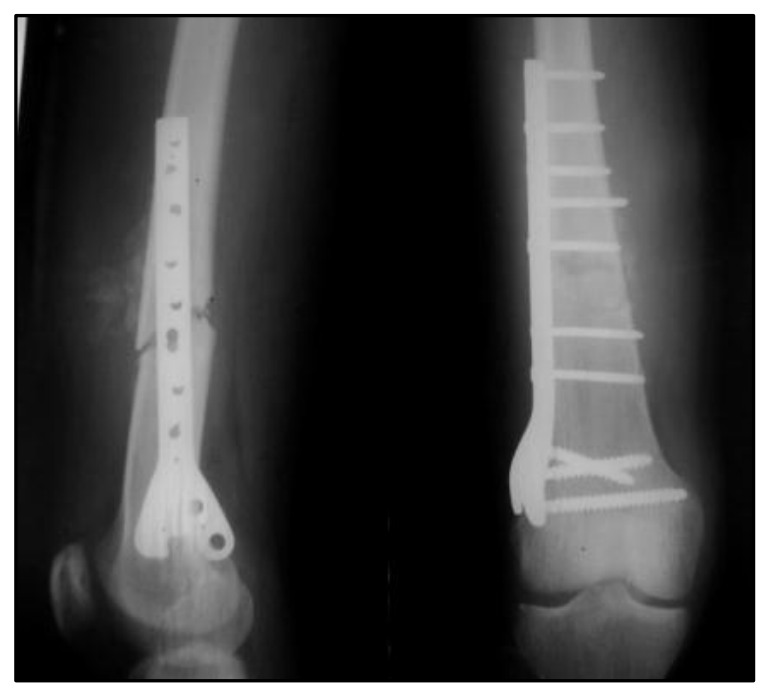

Post-op

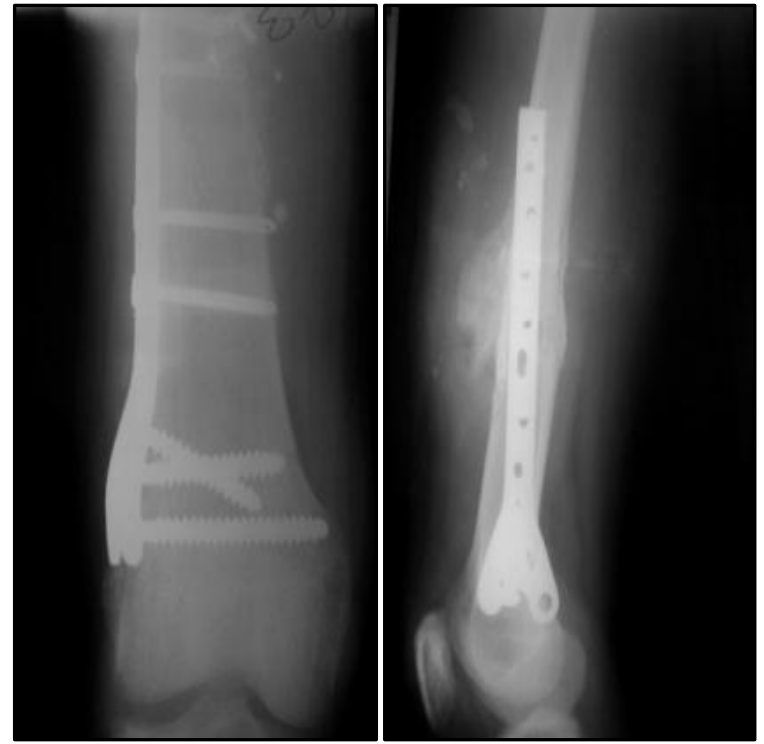

6 Months

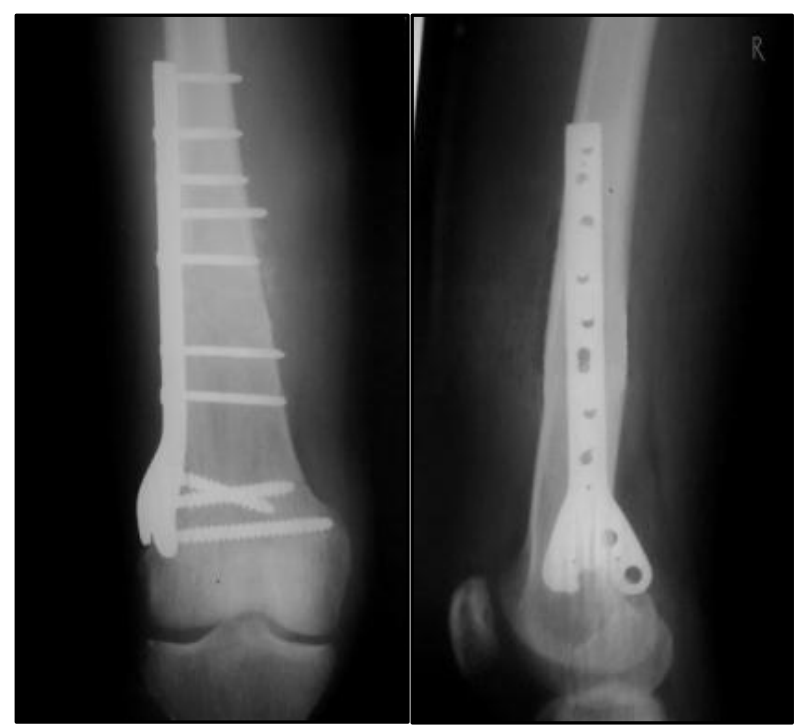

1 Year

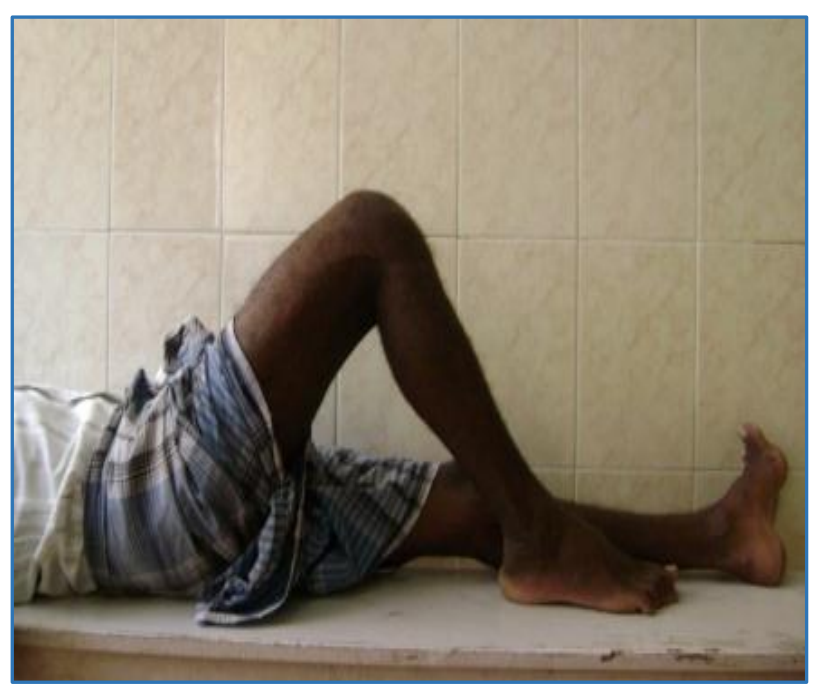

Knee Flexion 


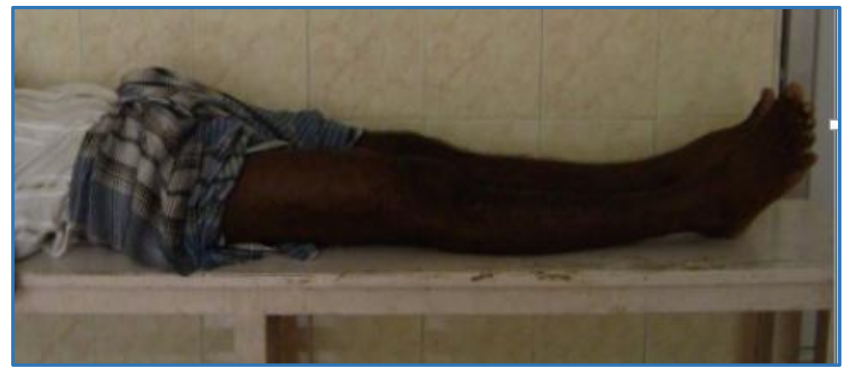

Knee Extension

\section{COMPLICATIONS}

\section{Knee stiffness:}

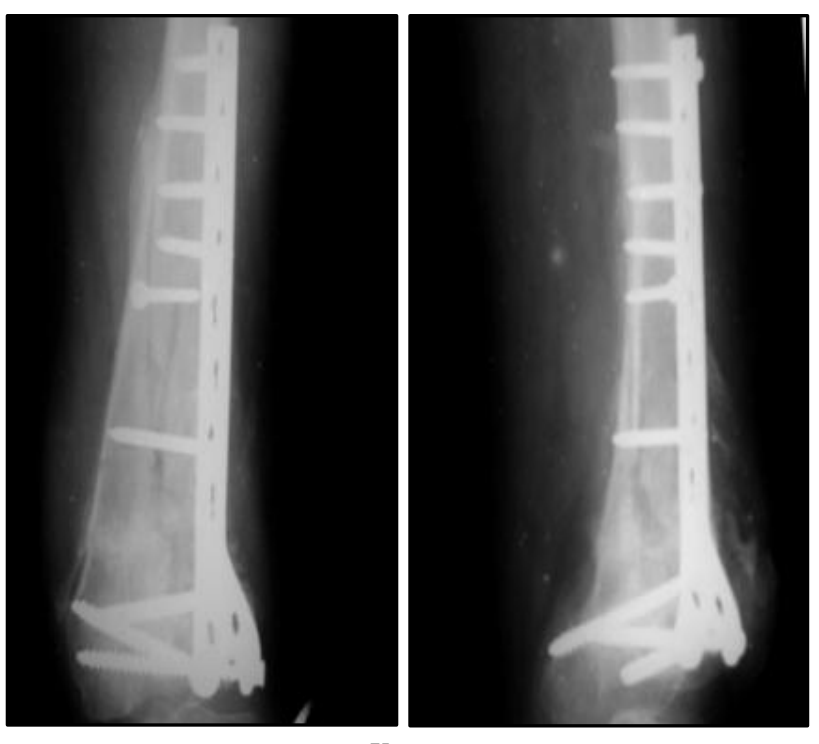

X-ray

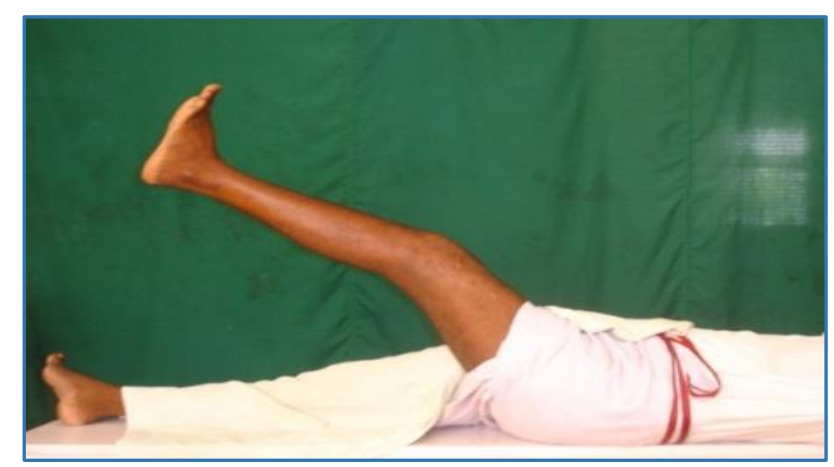

Clinical Picture

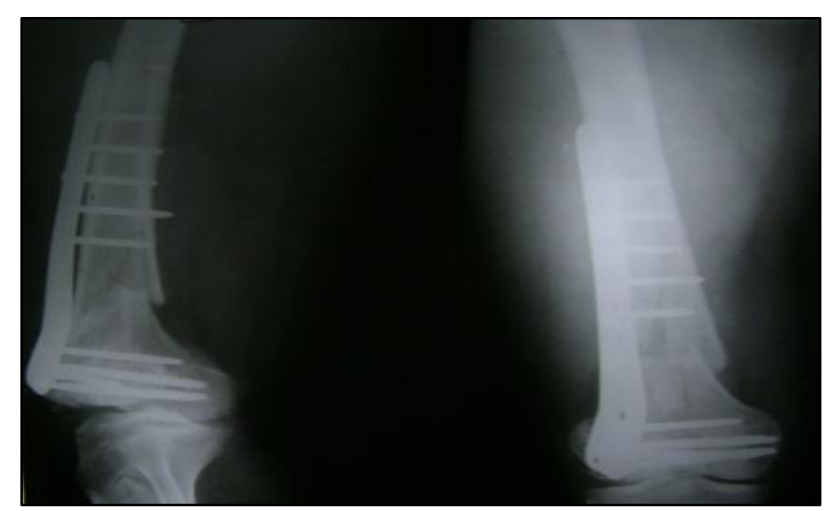

X-ray

\section{Clinical Picture}

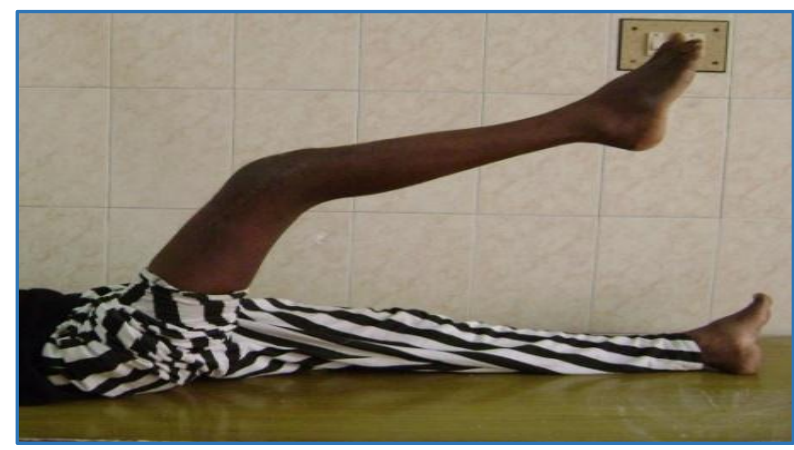

\section{CONCLUSION}

- Locking compression plating is one of the ideal method of internal fixation for both extra-articular and intraarticular fractures of the distal femur and it is very useful especially in metaphyseal fractures.

- Osteoporosis, loss of cancellous bone substance in the metaphyseal fractures leads to loosening of the screws which is better fixed with the locking compression plate.

- Combination techniques in highly comminuted metaphyseal fractures is also possible with the help of locking compression plate.

- The flexibility of this device with its fixed angle properties appears to offer an effective alternative to current implants for the treatment of a wide range of problematic distal femur fractures including comminuted intra-articular fractures and osteoporotic bone.

- Knee stiffness is the commonest complication especially in intra-articular distal femur fractures and infection is a common complication in compound fractures.

- Locking compression plate is gradually precluding the use of other methods of fixation.

\section{REFERENCES}

1. Muller ME, Allgower M, Willenegger $H$. Manual of internal fixation. Springer Verlag, Berlin and New York. NY: springer verlag, 1991;3rd edn.

2. Hoppenfeld Stanley, De Boer PIET. Surgical exposures in orthopaedics. Lippincott Wolter, 2009; $4^{\text {th }}$ edn.

3. Rockwood, Charles A, David P Green, et al. Fractures in adults and children. Lippincott Williams \& Wilkins, 2014;8 th edn.

4. Mahorner HR, Bradburn N. Fractures of the femur. Report of 308 cases. Surg Gynecol Obstet 1933;55:106679.

5. Yeap EJ, Deepak AS. Distal femoral locking compression plate fixation in distal femoral fractures. Malaysian orthop Journ 2007;1(1):12-7.

6. Hosam M, Khaled. Condylar plating in treatment of intercondylar supracondylar fractures of distal femur. Pan Arab J orth Trauma 2007;11(1):26-34.

7. Kanabar P, Kumar V, Owen PJ, et al. Less invasive stabilization system plating for distal femoral fractures. Journal of orthopaedic surgery 2007;15(3):299-302. 